\title{
CONTABILIDADE CRIATIVA E RESPONSABILIDADE DOS AUDITORES
}

\author{
Ariovaldo dos Santos \\ Professor Doutor do Departamento de Contabilidade e Atuária - FEA-USP \\ E-mail: arisanto@usp.br \\ Ivan Ricardo Guevara Grateron \\ Profesor de la Universidad Centroccidental Lisandro Alvarado - UCLA - Barquisimeto - Venezuela \\ E-mail: ivanrguevara36@ hotmail.com
}

\section{RESUMO}

Nos contextos nacional e internacional da profissão contábil, o auditor tem exercido um papel fundamental. A atividade profissional do auditor independente tem ajudado a impulsionar o desenvolvimento dos mercados, além de contribuir para o estabelecimento da ordem socioeconômica mundial. Na visão dos usuários externos da informação contábil, e dos próprios clientes, a atuação do auditor é sinônimo de confiança e credibilidade.

Nos últimos meses, a onda de escândalos contábeis, com grandes empresas de auditoria envolvidas, e até sentenciadas (no caso Enron, a Andersen foi considerada culpada, por um Júri de Houston - Texas, pela destruição de documentos), marcou a atividade profissional dos auditores e parece ter mudado a visão de responsabilidade desses profissionais sobre esses fatos.

No presente artigo são estudados e apresentados alguns conceitos fundamentais relacionados com o fenômeno da contabilidade criativa, assim como os fatores que induzem sua utilização, dentre os quais pode-se destacar: valores éticos, morais e vácuos ou flexibilidade normativa. Tais fatores acabam por funcionar como catalisadores da engenharia contábil no desenho das demonstrações contábeis e passam a atender os interesses de quem as elabora em vez de buscar a imagem fidedigna do patrimônio.

Palavras-chave: contabilidade criativa, responsabilidade do auditor, ética.

\section{ABSTRACT}

In the national and international contexts of professional accounting, the auditor has played a fundamental role. The professional activity of the independent auditor has both helped to encourage market development and contributed to the establishment of a global socio-economic order. From the point of view of the external users of accounting information and the clients themselves, the professional activity of the auditor is a synonym of trust and credibility.

In the last few months, the wave of financial scandals involving large auditing companies, some of which were even convicted for their demonstrated - direct and indirect - intervention in cooking the books, left marks in the professional activity of auditors, and changed the view on these professionals' responsibility for these facts.

This article studies and presents the basic concepts related to the phenomenon of earnings management, as well as the factors that induce it, among which we can highlight: ethical and moral values, loopholes or flexible accounting regulations. These factors end up acting as catalyzers of accounting engineering in the design of financial statements and start to serve the interests of those who elaborated them instead of seeking to give a true and fair view of the equity.

Keywords: earning management, auditor responsibility, ethics. 


\section{INTRODUÇÃO}

A expressão "Earnings Management", utilizada para se referir à Contabilidad Creativa, como tem sido freqüentemente traduzida para a língua espanhola ${ }^{1}$, ou, em português, Contabilidade criativa, como será utilizada no contexto deste trabalho, tanto na sua prática como quando é utilizada como estratégia empresarial, vem ganhando cada dia uma maior presença na informação contábil das empresas.

É importante considerar que a expressão earnings management deve ser desmembrada nas duas palavras que a compõem. De um lado a palavra management, que em português significa gerência ou manuseio, e, por outro, a palavra earnings, cujo significado é, fundamentalmente, o resultado. Assim, earnings management pode ser entendida como gerenciamento ou manuseio dos resultados, com a intenção de mostrar uma imagem diferente (estável no tempo, melhor ou pior) da entidade.

Diversos autores têm escrito sobre a tênue barreira que separa a chamada Contabilidade criativa da fraude contábil, ressalvando-se inclusive que alguns desses autores as tratam como sinônimas. A transparência na informação tem se convertido num requisito fundamental para o funcionamento dos mercados internacionais, e isso exige um conjunto de medidas, normas e regras com o objetivo de garantir que a "adequada" informação contábil chegue até seus usuários. Esse adjetivo, "adequada", atribuído à informação contábil, pode ser interpretado de muitas formas diferentes e deverá, neste trabaIho, ser entendido como a aplicação natural dos princípios fundamentais da contabilidade. Aparentemente, a aplicação das normas e regulamentos estabelecidos, tanto no âmbito legal como no normativo profissional, não tem conseguido seu principal objetivo no sentido de impedir ou diminuir a prática da Contabilidade criativa e quiçá deva apelar-se às suas implicações éticas.

Tal prática nem sempre tem sido evidente na informação contábil que as empresas oferecem; ao contrário, na maioria das vezes essa prática encontra-se escondida nas complexas demonstrações contábeis. Paralelamente, a função de auditoria se desenvolveu com muita rapidez e vem ocupando posições de grande importância na sociedade. A base desse desenvolvimento da profissão do auditor lastreou-se, fundamentalmente, na crescente necessidade das informações requeridas pelos usuários, previstas com a objetividade de um profissional independente que agrega credibilidade e fidúcia aos dados oferecidos pela entidade auditada.

O que se discute atualmente é se a responsabilidade do auditor deve restringir-se à emissão de um parecer que contenha sua opinião profissional, em relação à aplicação dos princípios fundamentais de contabilidade, ou também incluir a necessidade de informações atuais dos usuários, já que o modelo de parecer utilizado atualmente não foi concebido para ser utilizado para tomada de decisões. Nesse sentido, cabe a pergunta: deve-se requerer dos auditores uma posição mais clara sobre a adequação das demonstrações contábeis vis a vis as decisões que delas se podem inferir ou induzir, ou seja, deve-se requerer uma responsabilidade social maior do que aquela assumida até o presente momento? Em outras palavras, cabe perguntar se se pode exigir dos auditores opiniões que possam ser utilizadas para a tomada de decisões.

\section{PREMISSAS BÁSICAS}

O desenvolvimento do mundo dos negócios e a globalização têm impulsionado a necessidade mundial de organizar e padronizar ou harmonizar as práticas contábeis dos diferentes países. Essa padronização (que nos parece utópica) também deverá ser buscada nas técnicas de revisão e emissão de pareceres $^{2}$ por parte dos auditores.

As mudanças dos negócios e a globalização, aliadas ao desenvolvimento tecnológico, têm ocorrido com extrema rapidez e vêm deixando as empresas cada vez mais vulneráveis, obrigando-as a uma concorrência acirrada. Tal processo tem tornado as operações e transações das empresas cada vez mais numerosas e complexas, implicando demandas de serviços de auditoria cada vez mais adaptadas às

\footnotetext{
${ }^{1}$ Um dos autores é venezuelano.

${ }^{2}$ Em Bruxelas, a Comissão Européia está revisando a última versão sobre o Documento de Incompatibilidades que prevê mudanças no trabalho dos auditores e no parecer padrão. http://www.expansiondirecto.com/edicion/noticia/0,2458,132569,00html
} 
mudanças e, conseqüentemente, tornando mais vulneráveis as responsabilidades do auditor perante seus clientes e terceiros.

Esta situação, em muitos casos, tem obrigado os gestores da entidade a introduzir modificações, muitas vezes por via de artifícios nos registros contábeis, que são avalizadas nos pareceres de auditores independentes. De forma geral, os usuários entendem os pareceres dos auditores como um plus, ou valor agregado, de qualidade à informação e tomam o nome do auditor como um símbolo de credibilidade, confiança e segurança.

De alguns anos para cá, os resultados dos trabaIhos das auditorias independentes ultrapassaram os interesses específicos dos administradores das entidades auditadas. As próprias leis e normas que requerem esses serviços citam outros interessados indiretos. Em outras palavras, todos aqueles que, de alguma forma, tenham qualquer tipo de relação com a entidade auditada terão interesse na opinião dos auditores e nela basearão suas decisões. Tais interessados podem resumir-se nos seguintes grupos: investidores, credores, devedores, financiadores, reais ou potenciais, sindicatos de empregados e sindicatos patronais. Em outras palavras, o relatório do auditor tem usuários internos e externos iguais em importância e isso está consagrado nas Normas Internacionais de Auditoria, emitidas pelo Comitê Internacional de Práticas de Auditoria do International Federation of Accountants - IFAC, de cujo texto se pode extrair que a auditoria é um serviço que se presta à empresa auditada e que interessa não só a própria empresa, mas também a terceiros, evidenciando sua função social.

Os gestores das organizações, regra geral, se servem dos pareceres de auditoria para incluir ou tomar decisões de caráter econômico-financeiro e requerem informação objetiva e oportuna que lhes permitam que tais decisões sejam as mais adequadas. A informação que se oferece atualmente não permite identificar claramente as práticas de Contabilidade criativa existentes nas demonstrações contábeis, e a opinião do auditor, contida no parecer tradicional, não estabelece seu grau de responsabilidade com respeito a esse fenômeno, e isso, no atual contexto, pode acabar criando incertezas nos usuários.
A existência de práticas criativas pode induzir os administradores das entidades relacionadas à auditada, ou com interesses sobre ela, a tomar decisões erradas, inexatas ou, no mínimo, diferentes daquelas que tomariam se tivessem o mesmo conhecimento sobre a entidade que têm aqueles que prepararam e divulgaram as respectivas informações. As práticas de Contabilidade criativa distorcem a informação contábil e é provável, inclusive, que seja essa a principal razão de sua existência, pois modifica ou induz a matriz de decisões dos usuários.

É bastante comum encontrar, na bibliografia técnica, divergências profundas na delimitação do significado e as razões que motivam a inclusão das práticas de contabilidade criativa. A forma para definir a Contabilidade criativa utilizada por um autor pode ser completamente diferente da utilizada por outro. Assim, pode-se encontrar a utilização do termo contabilidade criativa como um sinônimo de manipulação contábil, maquiagem contábil, arbitrariedade contábil e até como uma técnica para "melhorar" o conteúdo da informação contábil. Em nossa opinião, a contabilidade criativa não pode ser entendida apenas como uma forma de manipulação dos resultados da entidade. Ela é muito mais ampla e deve considerar outras alterações que podem ser feitas no sentido de se alterarem, além dos resultados, itens que possam mascarar a apuração de índices ou coeficientes, calculados com base nas demonstrações contábeis.

Com o estudo e análise da responsabilidade que poderiam ter os auditores independentes sobre a existência de práticas de Contabilidade criativa nas demonstrações contábeis de seus clientes, pretende-se oferecer uma contribuição aos usuários da informação contábil, reais e potenciais, e, muito especialmente, aos auditores que começam seus passos nessa fascinante atividade profissional. Para isso, serão necessárias a discussão e a análise de aspectos relevantes, que têm sido objeto de amplas e profundas reflexões por parte dos profissionais que trabalham em empresas de auditoria e por pesquisadores e profissionais relacionados a essa atividade.

As demonstrações contábeis das entidades têm sido, até o presente, uma das maneiras como a organização se comunica com o mundo exterior; ao mesmo tempo, têm sido o resultado da aplicação de 
princípios e normas de contabilidade que buscam, fundamentalmente, a consecução de informação fidedigna, real, objetiva e oportuna, que sirva aos diferentes tipos de usuários. Através do processo de auditoria, a entidade busca um profissional, independente da organização, que lhe possa agregar essa credibilidade requerida pelos usuários da informação.

Em resumo, com a falta de harmonização contábil, a falta de especificidade das normas existentes e a conseqüente margem de interpretação e arbitrariedade na aplicação que isso permite, pode-se identificar um problema de comunicação que afeta os emissores da informação contábil e muito mais seus usuários.

\section{O ESTÁGIO DA CONTABILIDADE CRIATIVA COMO FENÔMENO CONTÁBIL}

Muitos são os fatores que favorecem o exercício da criatividade contábil, mas talvez o maior dos incentivos seja a impunidade, em todos os sentidos (jurídico, social, mercantil, etc.) do manipulador da informação. Os auditores citam as seguintes causas como origem da contabilidade criativa:

a) Características dos princípios e normas contábeis:

- existência de múltiplas estimativas;

- flexibilidade, arbitrariedade e subjetividade na aplicação;

- diferentes, porém válidas, interpretações dos princípios e normas contábeis;

- conceito base de Imagem Fidedigna pouco claro ou indeterminado; e

- cuidados da administração na aplicação de princípios como prudência, confrontação de receitas e despesas e uniformidade.

b) Características sociais e de comportamento humano:

- valores éticos e culturais; e

- atitude do administrador diante da fraude.

Como se pode observar, para a prática da contabilidade criativa, o gerente utiliza, principalmente, a flexibilidade dos princípios e normas contábeis a que a empresa se obriga. Mesmo apresentando certas restrições, no que se refere à elaboração, tratamento e apresentação da informação contábil/financeira, em muitos casos contempla a prudência para a es- colha dos procedimentos que melhor se adaptem aos requerimentos estratégicos da organização, algumas vezes em detrimento dos interesses dos usuários da informação.

A contabilidade criativa tem se desenvolvido em todas as áreas, sendo cada vez mais comum, com práticas que têm sido cada vez mais complexas, demandando de seus criadores profundos e detalhados conhecimentos técnicos e tornando mais difícil sua identificação. De um lado, parte dos administradores e gerentes da empresa utiliza a informação contábil para mostrar a cara que desejam que seus usuários conheçam, mesmo que esta não seja a mais fidedigna. Por outro lado, diversos usuários se valem da informação contábil e financeira produzida e divulgada pela empresa, mesmo que alguns dados nem sempre estejam presentes, ou até estejam apresentados de maneira confusa para dificultar sua compreensão.

\subsection{Uma revisão bibliográfica sobre o tema}

Antes de abordar os conceitos técnicos específicos utilizados neste trabalho, é conveniente definir alguns termos que se consideram fundamentais. $O$ Novo Dicionário Básico da Língua Portuguesa, do professor Aurélio Buarque de Holanda Ferreira, define Auditoria como "Exame analítico e pericial que segue o desenvolvimento das operações contábeis, desde o início até o balanço". Gestão, por sua parte, é definida como "Ato de gerir; gerência, ou administração".

Uma das correntes que estuda a Contabilidade criativa, mais especificamente a anglo-saxônica, a define como um conjunto de técnicas e práticas realizadas por parte de um gestor com a finalidade de manipular e obter um nível de resultados (lucros ou prejuízos) desejado. Outros a definem como a seleção das melhores alternativas, válidas do ponto de vista da norma aplicável, utilizando-a como sinônimo de estratégias criativas. Estes extremos, passando por diferentes estágios intermediários, evidenciam que uma definição consensual é praticamente impossível.

O IFAC (1997), define que "O objetivo de uma auditoria das demonstrações contábeis é habilitar o auditor a expressar uma opinião sobre se as demons- 
trações foram preparadas, em todos seus aspectos relevantes, de acordo com uma estrutura conceitual identificada para relatórios contábeis." IBRACON (1998, p. 23).

O termo gestão normalmente é associado a administração, e algumas vezes utilizado como seu sinônimo. Para o professor NAKAGAWA (1987, p. 50), da Universidade de São Paulo, o termo gestão tem a conotação da palavra inglesa manage, permitindo deduzir-se o envolvimento do ato de conduzir ou gerenciar. Esse autor define gestão como "a atividade de conduzir uma empresa ao alcance de um resultado desejado (planejado) por ela, apesar das dificuldades".

Por outro lado, se revisarmos, no contexto do Direito Internacional, o significado etimológico e jurídico da palavra fraude, encontraremos que se refere à tergiversação da verdade com intenção de enganar e pela qual se causam danos a terceiros, que normalmente são de caráter econômico. Em nossa opinião, qualquer manipulação da informação contábil que contenha uma distorção na conformação correta desta deve ser entendida como uma espécie de fraude.

A fraude é definida nas Normas Internacionais de Auditoria (IFAC, Tema 240, p. 53) como: "um ato intencional por parte de um ou mais indivíduos dentre os membros administrativos, empregados ou terceiros, que resulta em declarações falsas das demonstrações contábeis". Feitas essas considerações, é conveniente revisar o que alguns autores definem como Earnings Management para poder entender o amplo sentido que este termo envolve, e assim poder sustentar as afirmações finais.

De forma geral, o termo em questão tem sido utilizado para referir-se ao processo mediante o qual os contadores aplicam os conhecimentos da norma contábil para manipular, de acordo com sua conveniência, os valores das demonstrações contábeis. Vários autores, citados por AMAT (1997, p. 11-12), expõem seus argumentos e definem o termo desde suas diferentes perspectivas, ou seja, de jornalista, especialista contábil, analista de investimentos e acadêmicos, tal como se mostra a seguir.

Para o jornalista econômico GRIFFITHS (1986, p. 1), a contabilidade criativa tem um singular significado. Apesar de não ser um especialista da área contábil, consegue apresentar uma definição muito coerente com a de autores reconhecidos na área: "Todas as empresas do país estão escondendo seus resultados. Os resultados anuais se baseiam em livros que têm sido 'cozinhados' ou 'completamente assados'. As demonstrações apresentadas duas vezes ao ano ao público investidor têm sido todas manipuladas para proteger os culpados. ... De fato esta fraude é completamente legítima. É a contabilidade criativa".

Por outro lado, o especialista contábil JAMESON (1988, p. 8-9) afirma: "O processo contábil consiste em tratar com diferentes tipos de opiniões e resolver conflitos entre aproximações diferentes, para apresentação dos resultados, dos fatos e transações financeiras. Essa flexibilidade facilita a manipulação, mentira e tergiversação. Estas atividades - praticadas por elementos menos escrupulosos da profissão contábil - começam a ser conhecidas como Contabilidade criativa".

Outra perspectiva diferente é apresentada por SMITH (1992, p. 4-6), que, baseando-se em sua experiência como analista de investimentos, afirma: "Nos dá a impressão que grande parte do aparente crescimento, ocorrido no final dos anos 80 , tenha sido mais um resultado da manipulação contábil do que um verdadeiro crescimento econômico, e queremos expor as principais técnicas utilizadas e dar alguns exemplos de empresas que as estão utilizando."

Nesta análise não pode ficar de fora o ponto de vista de um acadêmico. Neste sentido, NASER (1993, p. 2) define a contabilidade criativa como: "a transformação das cifras da contabilidade financeira uma vez que são, na atualidade, o que se deseja que sejam, aproveitando as normas existentes e/ou ignorando algumas delas".

O próprio AMAT (1997, p. 9-11) expõe que a Contabilidade criativa consiste na manipulação que se faz da informação contábil, aproveitando-se dos vazios das normas existentes e as possíveis alternativas que têm o gerente à sua disposição sobre as diferentes práticas de avaliação utilizadas.

Como se pode notar, até este ponto todos os autores citados entendem que existe manipulação da "verdadeira" informação, alegando-se causas ou motivos de questionável aceitação do ponto de vista da ética profissional, qualquer que seja a área de atividade. 
Também se observa expressamente em forma subjacente nas afirmações dos autores anteriormente citados, a referência ao não cumprimento de certos parâmetros e a alusão à fraude, ambos relacionados amplamente com valores éticos. Mais especificamente, por exemplo, GRIFFITHS (1988, p. 11-14) assinala em seu artigo frases como "escondendo benefícios", "livros contábeis cozinhados ou assados", "as cifras que se mostram aos investidores têm sido manipuladas para proteger os culpados". Possivelmente, essas frases, comuns nas definições dos autores, servem para suportar com muita força a hipótese da grande implicação dos valores éticos dentro da contabilidade criativa, mesmo que não seja difícil encontrar quem se negue a admiti-lo.

GRIFFITHS (1988), citado por LAINEZ (1999, p. 17), apresenta a contabilidade criativa em uma posição intermediária entre o que é legal e o que é ético; entre a criatividade e a fraude contábil. Griffiths ainda utiliza o adjetivo "artimanhas", de forma pejorativa, para definir a contabilidade criativa e acaba por afirmar que tais artimanhas "são legítimas e não infringem as regras do jogo", abrindo mais a brecha que separa a norma de seu espírito em qualquer âmbito de aplicação. GRIFFITHS (1995, p. 20-24) também descreve a Contabilidade criativa como a manipulação da realidade da empresa para se chegar em uma informação que reflita a situação desejada e não a real.

Por sua parte, JAMESON op. cit. faz uma reflexão mais coerente com nosso ponto de vista ético, ao afirmar que a contabilidade criativa opera embaixo da sombra da lei e das normas contábeis, e que por isso está em contradição com o espírito de ambas, qualificando-a como uma prática, no mínimo, inadequada.

Outros autores que têm escrito mais recentemente sobre a contabilidade criativa apresentam posições um pouco mais radicais. Da mesma forma que Griffiths, Jameson e Amat, MONTERREY em 1997, em seminário apresentado em Madrid Espanha - sustentou que a contabilidade criativa está formada pela manipulação de valores contábeis através da flexibilidade, imprecisão ou inexistência de normas contábeis, que são utilizadas individualmente ou em conjunto, para obter e apresentar os valores desejados nas demonstra- ções contábeis, o que não é nada novo. Contudo, agrega Monterrey que a prática da contabilidade criativa exige a não aplicação das normas e princípios contábeis ou o abandono de sua aplicação uniforme; essa posição é diferente da oferecida pelos autores anteriores que consideram a contabilidade criativa dentro da margem de cumprimento da norma contábil aplicável.

Se nos referirmos ao significado jurídico e à origem etimológica da palavra fraude, apresentada previamente, em seu conceito aparecem as mesmas palavras que se utilizam para descrever a contabilidade criativa. No sentido jurídico da palavra fraude, deve existir a culpa e/ou culpado. Poderíamos, então, afirmar que este culpado, no contexto da contabilidade criativa, se refere ao gestor da empresa? Será que quando o autor afirma na frase "escondendo resultados", isso deve ou pode ser interpretado como uma forma de ocultar a verdade para enganar ou prejudicar terceiros? Como vemos, o debate a esse respeito parece ser sumamente controverso, contudo cremos que poderá ser amenizado se a análise restringir-se ao campo da ética profissional.

O conceito de fraude antes tratado, que corresponde à premissa básica deste estudo, coincide completamente com o desenvolvimento das Normas Internacionais de Auditoria do IFAC que estabelecem que "Ao planejar e executar procedimentos de auditoria e ao avaliar e relatar seus resultados, o auditor deve considerar o risco de distorções relevantes nas demonstrações contábeis, como resultado de fraude ou erro." O mesmo texto, na referida Norma Internacional de Auditoria, estabelece que o termo fraude "referese a um ato intencional por parte de um ou mais indivíduos dentre os membros administrativos, empregados ou terceiros, que resulta em declarações falsas das demonstrações contábeis." Agrega, também, que a fraude pode envolver:

- manipulação, falsificação ou alteração de registros ou documentos;

- apropriação indébita de ativos;

- supressão ou omissão dos efeitos de transações nos registros;

- registro de transações sem comprovação; e

- aplicação indevida de políticas contábeis. 
Por sua parte, JAMESON op. cit. identifica a contabilidade criativa dentro dos conflitos que podem existir nas diversas alternativas sob as quais o gestor ou contador podem construir as demonstrações contábeis. Se observarmos a flexibilidade entre os diversos critérios que o autor cita como fonte de manipulação para consumar o "engano" contábil, talvez devêssemos estar completamente de acordo. Contudo, se colocarmos como parâmetro o "dever ser", guiado pelos princípios e valores éticos do profissional, é possível que o gestor possa diferenciar facilmente entre decisões contábeis e arbitrariedade.

É oportuno considerar que a contabilidade criativa está sempre localizada entre: a) a existência de normas, regras ou parâmetros inexatos, pouco específicos ou pouco detalhados que permitem sua diferenciada interpretação e, por conseqüência, sua particular aplicação e b) a inexistência de tais preceitos normativos; é possível que os organismos nacionais, colegiados ou associações profissionais regulem determinadas práticas com finalidade puramente econômica e não ética. Isso significa o mesmo que dizer que a contabilidade criativa pode ser originada por uma lei e/ou norma/regulamento e também pela ausência desses instrumentos legais.

Para LAINEZ \& CALLAO (1999, p. 28-31), existe um componente adicional que deve ser considerado ao estudar a contabilidade criativa e que, no nosso modo de ver, complica a análise desse conceito. Assinalam os autores que a existência da contabilidade criativa está determinada pela flexibilidade e subjetividade da norma; contudo, acrescentam que o componente fundamental que determina a existência dessa contabilidade criativa é a intenção do emissor da informação ao fazer uso dessa flexibilidade, subjetividade, dubiedade e imprecisão para obter os resultados desejados. Isso significa dizer que é praticamente impossível identificar a contabilidade criativa nas demonstrações contábeis. A análise da intenção de quem constrói e apresenta resultado manipulado é altamente subjetiva e sempre será um componente que se presume, mas que raramente se pode comprovar.

Até o presente tem-se a contabilidade criativa como uma atividade inadequada e de pouca aceitação, principalmente quando se considera o efeito distorcido que provoca nas informações contábeis. Alguns organismos como a Security and Exchange Commission (SEC), o American Institute of Certified Public Accountants (AICPA) e o International Federation of Accountants (IFAC) estão trabalhando para limitar e reduzir o crescimento da prática da contabilidade criativa, já que consideram que sua utilização pode ter efeitos perniciosos consideráveis, inclusive no âmbito macroeconômico, como os que estão presenciando, por exemplo, os Estados Unidos da América com os escândalos contábeis da Enron e WorldCom, entre outros não menos importantes. Isso nos permite inferir que será muito difícil descobrir aqueles que, valendo-se de seus apurados conhecimentos técnicos-contábeis, manipulam os dados da entidade para obter e apresentar situações irreais.

Acreditamos que a intenção representa um elemento importante para qualificar as práticas criativas como "más ou piores", pois isso representa um agravante e não um elemento que permita diferenciar os tipos de contabilidade criativa. A dificuldade ou impossibilidade de identificar a intenção dos gestores nos leva a não considerar este elemento, apesar de reconhecer sua grande importância.

Para todos os autores citados, e outros não incluídos neste trabalho, parece ser coincidente que o termo "manipulação de resultados" associado à contabilidade criativa está identificado por dois fatores fundamentais:

- resultado de uma atitude consciente ou produto da vontade de manipular as demonstrações contábeis; ou seja, apresenta-se uma informação que não coincide com a que se poderia qualificar como "mais objetiva". Por esta razão, o objetivo dessa prática é confundir ou enganar os usuários acerca da situação real da entidade; e

- para todos os autores, a contabilidade criativa é vista como uma concepção pejorativa da atividade e que contraria os princípios da ética profissional.

Por outro lado, CANO (2002, p. 2-3) estabelece que existem outros dois aspectos ou fatores que denotam as diferenças nas definições dos diferentes autores. Os primeiros desses fatores são denominados, pelo autor, "manipulação real" e 
"manipulação contábil", que a seguir são explicados: "Determinados autores incluem em suas definições tanto as decisões estritamente contábeis por exemplo, aquelas referidas na eleição de critérios contábeis ou as estimativas necessárias para levar a cabo a contabilidade (métodos de amortização, métodos de avaliação de estoques, ativação ou não de despesas...), como aquelas que teriam um efeito nas transações reais e não só em seu reflexo contábil (redução de orçamento, de despesas, decisões sobre capital circulante líquido, postergação de investimentos...). Outros autores, pelo contrário, consideram como contabilidade criativa somente as alterações estritamente contábeis, considerando as decisões sobre as transações reais como uma atividade lícita por parte dos gestores, totalmente independente dos artifícios contábeis". (tradução livre)

O segundo dos fatores diferenciadores dos conceitos dos autores apresentados é o que se refere ao alcance das práticas de contabilidade criativa. Assim, por um lado alguns autores consideram que devem definir-se como práticas criativas aqueles comportamentos que, mesmo com a transgressão ao espírito da norma contábil, não atentem expressamente contra seu conteúdo. Exemplo disso é a utilização de lacunas legais existentes ou de ambigüidade em sua interpretação. Por outro lado, outros autores consideram como contabilidade criativa não só aquelas práticas de interpretação conveniente das normas, mas também aquelas ações que infringem ou ignoram tais normas. Pesquisas empíricas realizadas em países chamados "do primeiro mundo" destacam que, dentro das principais motivações para manipulação contábil, os incentivos econômicos, tanto para os gestores como para as próprias empresas, são os mais freqüentes impulsionadores da contabilidade criativa. Entre os incentivos mais comuns podem-se mencionar os seguintes exemplos:

1. Obtenção de benefícios diretos sobre os resultados alcançados, margens das vendas, participação no mercado;

2. Obtenção de concessões, bonificações e prêmios extras;

3. Melhoria da imagem para inclusão no mercado financeiro (bolsas de valores e financiamentos externos);
4. Obtenção ou manutenção de subvenções para a indústria, ramo de atividade ou setor;

5. Alcançar medidas de proteção das agências governamentais e organismos internacionais de financiamento;

6. Obtenção de benefícios fiscais através da isenção e redução das bases de tributação;

7. Controle de dividendos; e

8. Estratégias competitivas e de mercado, além de outras não menos importantes.

Parece que será muito difícil justificar a boa intenção dos gestores ou profissionais da contabilidade no sentido de manipular dados que busquem uma suposta "imagem mais fidedigna do patrimônio". As questões que se poderiam colocar são: Para quem e sob quais argumentos as demonstrações contábeis serão mais confiáveis? Será possível haver homogeneidade na informação contábil?

\section{CONSIDERAÇÕES DE CARÁTER ÉTICO EM RELAÇÃO À CONTABILIDADE CRIATIVA}

É evidente que o desenvolvimento da atividade profissional dos auditores requer um componente comportamental. Muitas vezes, o processo de tomada de decisões pode estar mais ligado aos princípios e valores éticos elementares do que aos aspectos técnicos. Continuamente o auditor é submetido a questões de caráter ético, devendo adotar uma de várias alternativas de decisão, muitas vezes assumindo riscos relacionados com a boa imagem do profissional.

A ética é um princípio fundamental e necessário para o bom funcionamento da sociedade, especialmente para o exercício de diferentes profissões entre as quais se inclui a do auditor. Entendemos que a formação ética de um profissional definirá sua conduta no futuro e isso, conseqüentemente, se refletirá na cultura e respectiva saúde econômica de seu país. Tal como escreve KNECHEL (1997, p. 422), "uma das restrições mais importantes que tem a pessoa que toma decisão na hora de fazê-lo é seu código pessoal de ética ou moral. A ética pessoal não muda a natureza do processo de auditoria, mas a sensação individual de se fazer as coisas corretamente e não se equivocar terá um impacto direto na hora de definir o problema, estudar os critérios e avaliar as 
alternativas possíveis em cada decisão" (tradução livre). Por isso, pode-se afirmar que o comportamento ético é bastante relevante para se poder entender o conceito abstrato, muito utilizado pelo auditor, que é o juízo profissional.

A pesquisa ética se concentra na solução dos potenciais conflitos éticos que são produzidos como resultado da confluência de diferentes interesses sobrepostos, o qual tem sido denominado pelos pesquisadores como "o dilema ético". Nesse sentido, podemos estabelecer uma relação direta e proporcional entre o crescimento das empresas e a complexidade de suas operações com o aumento de demandas e litígios contra os auditores.

Como demonstrado na primeira parte, a inclusão de práticas criativas de contabilidade nas demonstrações contábeis das empresas pode ser um problema legal, técnico de interpretação ou ético moral. Cada uma dessas posições é defendida por diferentes autores. Depois das considerações éticas descritas neste ponto, o que parece ser claro é que em todos os casos o componente ético-moral está presente, ou seja, tanto nos conflitos de interpretação dos aspectos técnicos quanto nos de aplicação e cumprimento das normas legais.

Neste sentido, segundo WILLIANSON (1990), citado por SIERRA e outros (2001, p. 47-59), existem três níveis principais de responsabilidade que sustentam um sistema de disciplina:

a) a responsabilidade legal que é imposta pelos códigos de conduta da sociedade como requisito mínimo para quem recebe um reconhecimento profissional;

b) a responsabilidade moral que são os códigos de conduta que as pessoas se impõem a si mesmas, normalmente de forma consensual. Essa responsabilidade exige um padrão de conduta superior ao requerido pela responsabilidade ética. Pode ser de caráter individual ou de uma associação de profissionais, como as empresas de auditoria; e

c) a responsabilidade ética, que é a que se impõe a um conjunto de profissionais sobre seus membros para assunção voluntária de responsabilidades, pelo interesse público, diante dos colegas, clientes e a comunidade (Códigos de Ética Profissional).
Por outro lado, CARMICHAEL e outros (1996, p. 46) identificam cinco preceitos chamados por eles "Princípios da Ética" que, como veremos, se adaptam perfeitamente ao exercício profissional do auditor. Estes preceitos são: a) Independência, integridade e objetividade; b) normas gerais e técnicas; $c$ ) responsabilidade com seus clientes; d) responsabilidade com os colegas e; e) outras responsabilidades e práticas.

Outros conceitos que devem ser citados são os códigos de ética descritos pelos Guias de Auditoria publicados pelo IFAC, os quais estão orientados no sentido de melhorar a qualidade dos trabalhos de auditoria, objetivando satisfazer as quatro necessidades principais dos clientes e os usuários em geral, ou seja: 1) Credibilidade; 2) Profissionalismo; 3) Qualidade dos serviços; e 4) Confiança.

SHAFER et al. (2001, p. 256) afirmam que os valores pessoais exercem uma notável influência sobre a tomada de decisões no contexto das organizações e dos negócios. O efeito potencial que têm os valores éticos nos modelos de decisão gerencial e pessoal sobre os modelos de decisão empregados é amplamente reconhecido na atualidade, demonstrando a estreita relação que têm as práticas criativas com o sistema de crenças e valores dos gestores e da própria entidade, e todos eles exercem um efeito significativo sobre o trabalho do auditor.

\section{CONSIDERAÇÕES SOBRE A RESPONSABILIDADE DO AUDITOR}

O termo "Responsabilidade" está muito relacionado à atividade do auditor, e falar de um sem mencionar o outro seria muito difícil. No âmbito internacional, o termo inglês Accountability parece ser o mais indicado para definir a responsabilidade dentro do âmbito da atividade do auditor independente. Para DÁVILA-GUZMÁN (1991, p. 18), responsabilidade: "É a obrigação de responder a uma tarefa que Ihe tenha sido conferida e pressupõe a existência de, pelo menos, duas pessoas: a que confere ou outorga a responsabilidade e a que aceita com a obrigação de prestar contas sobre a maneira como a exerceu." Acrescenta em seguida o mesmo autor que "Prestação de contas é a obrigação assumida, por aqueles que exercem 
autoridade, de reportar sobre a forma como a autoridade foi exercida." (Traduções livres)

No trabalho do auditor, a norma internacional exige a apresentação de um relatório ou parecer com a opinião imparcial e independente sobre o resultado da revisão efetuada, o que se pode considerar como a prestação de contas do auditor.

A importância de alguns fracassos empresariais acompanhados de irregularidades na apresentação da informação contábil e financeira referente à empresa tem conseguido macular a imagem de objetividade e independência do auditor e tem sensibilizado a opinião pública, fundamentando sérias dúvidas sobre a capacidade profissional dos auditores e da responsabilidade que se espera que assumam diante de seus atos e omissões. Isso é o que afirma Juan del CID (1994, p. 827).

Na Norma Internacional do IFAC está escrito que os auditores serão responsáveis por todos os prejuízos causados a terceiros como conseqüência do descumprimento de suas obrigações profissionais, entendendo-se por obrigações profissionais o cumprimento rigoroso das normas que regem o desenvolvimento da atividade profissional; contudo, a falta de especificações sobre as mencionadas obrigações e os casos de descumprimento que ocasionam responsabilidade não estão claramente definidos, não só nas normas de caráter nacional de cada país, mas também na norma internacional do IFAC que tem sido utilizada como modelo.

Devemos destacar que a mencionada norma descreve como objeto de auditoria a emissão de um relatório, com a opinião profissional sobre a fidelidade da informação prestada pela administração, a fim de que seja avaliada e conhecida por terceiros. Isso permite afirmar que no trabalho do auditor está implícito seu caráter social, pois considera a necessidade de responder às expectativas dos usuários da informação contábil e financeira.

Como dito anteriormente, os auditores não aceitam a responsabilidade pelos fracassos empresariais, nem sequer a relação desses fracassos com o processo de auditoria. Tampouco aceitam a responsabilidade pela emissão de informação "manipulada com dados falsos" com a utilização da Contabilidade criativa, o que poderia ser considerado como conduta fraudulenta, tal como foi descrito no início deste trabalho. Para os usuários, de outro lado, a percepção sobre a responsabilidade dos auditores é mais que evidente. Na maioria dos casos, quando os auditores são questionados sobre os fracassos empresariais de seus clientes, a reação instintiva os leva a declarar que a administração da empresa é de inteira responsabilidade do cliente e que seu fracasso é oriundo de práticas de gestão; contudo, a diferença entre as expectativas geradas pelo auditor com seu trabalho e as esperadas pelos usuários parecem cada dia mais distantes.

Para os auditores parece estar bastante clara a delimitação de responsabilidades, contudo é evidente a existência de um "gap" ou diferença, com respeito à responsabilidade que os usuários esperam deles por seu trabalho profissional. Atualmente se discute a necessidade de definição clara da responsabilidade dos auditores nos fracassos empresariais de seus clientes. Apesar de não estarem obrigados a evitá-los, pode se dizer que os auditores têm uma grande responsabilidade social, e também com seu cliente, de identificar possíveis indicadores de fracassos para alertar a própria administração e seus usuários.

É possível que diante de uma situação delicada a empresa proceda de maneira mais agressiva, podendo recuperar-se ou falir. Neste caso, o auditor está obrigado a reconhecer que terá sua responsabilidade se não alertar em seu relatório uma possível conseqüência negativa como produto da agressividade da Direção. Lamentavelmente, o problema discutido é de caráter conceitual apenas para os pesquisadores e acadêmicos; para os auditores prevalece o interesse profissional e isso pode ser entendido como corporativismo.

Quando se discute sobre os termos de responsabilidade dos auditores e as diferentes expectativas sobre seu trabalho, é importante destacar a definição de alguns aspectos como: 1) a responsabilidade que tem e a que aceita o auditor pela detecção e comunicação de fraudes e irregularidades; 2) posição e imagem independente do auditor com seus clientes frente a isso e a comunidade em geral; 3) compromisso de serviços públicos dos auditores ou responsabilidade social; e 4) significado da utilidade da informação para clientes e usuários externos. 
Mesmo que pareça estar claro para os auditores, de acordo com as normas profissionais emitidas no âmbito internacional, o fato é que os auditores não têm assumido nenhum tipo de responsabilidade pela não detecção de erros e irregularidades que provoquem fraudes. Segundo a norma de auditoria SAS 82 e $99^{3}$, só em caso de tais irregularidades atingirem materialidade significativa, o auditor assume a responsabilidade pela não detecção. Contudo, a imprecisão utilizada para definir este ponto tem sido objeto de grandes debates.

Não podemos nos esquecer que a profissão de auditor nasceu com a intenção de cuidar do patrimônio de seus clientes contra manuseios indevidos dos empregados, objetivo que evoluiu no tempo até converter-se no que atualmente representa de forma indiscutível: emitir uma opinião profissional independente sobre a veracidade e fidelidade da informação contida nas demonstrações contábeis de seus clientes.

Esta última afirmação é consistente com o fato de que, de acordo com as próprias normas internacionais da profissão, para chegar à opinião profissional antes descrita é necessário e obrigatório elaborar um plano de auditoria que possa detectar irregularidades significativas, escusando-se de responsabilidade pela não detecção de outras de menor importância. É possível que estes tipos de divergências, distâncias, diferenças de princípios contábeis sejam diminuídos se se fizer uma revisão do caráter autoregulador da profissão.

Cabe ressaltar que na atualidade, talvez como uma forma de resposta diante desta marcada e evidente diferença de expectativa, ou simplesmente uma nova fonte de receita, algumas empresas de auditoria como Ernst \& Young e Coopers \& Lybrand, atualmente PricewaterhouseCoopers, oferecem serviços específicos para detectar e prevenir fraudes. Como é lógico, o marcado desenvolvimento da profissão nos últimos anos gerou as correspondentes expectativas nos clientes e usuários na mesma proporção que a velocidade do dito crescimento e desenvolvimento.

Fica evidente que existe um divórcio entre a função da auditoria independente e as necessidades de informação dos usuários, convertendo-se em um problema da profissão que ultrapassa fronteiras. Mesmo assim, a existência de práticas criativas que desvirtuam o objetivo descrito na norma internacional de auditoria representa um dos mais importantes problemas atuais da profissão do auditor, principalmente se se considerar sua responsabilidade social assumida ou aquela que se espera que deveriam assumir.

\section{1 - O papel do auditor frente ao fenômeno da Contabilidade criativa}

Para analisar a relação que guarda o auditor com a contabilidade criativa, é importante definir quais são as possibilidades de manipulação das informações contábeis. Os incentivos que podem levar os administradores a realizar práticas criativas, com a intenção de mostrar a seus usuários uma imagem diferente da "real", são múltiplos, contudo podem ser agrupadas em três grandes categorias. Nesse sentido, a empresa pode optar por mostrar uma imagem melhorada, deteriorada ou estável, em comparação com a imagem "natural ou real".

Em nossa opinião, é de ampla aceitação a afirmação de que o profissional de auditoria desempenha um papel importante no grau de confiança que depositam os usuários da demonstração contábil e na relativa garantia que devem suportar as decisões dos entes com base nas demonstrações auditadas e, inclusive, que representem o suporte do mercado financeiro, o qual pode evidenciar-se se estudarmos o conteúdo do parecer do auditor, ao menos em algumas de suas frases mais importantes.

Os conhecedores da atividade de auditoria entendem com facilidade o alcance da opinião do auditor; essas pessoas, normalmente, sabem como interpretar e tratar cada parágrafo do parecer do auditor. Contudo, é bastante comum entre os usuários menos advertidos considerar, por exemplo, um parecer limpo ou sem ressalvas como uma garantia total de que todas as demonstrações contábeis que o acompanham são corretas e exatas. Talvez isso se deva ao conteúdo e significado altamente técnico das frases que compõem o parecer padrão tais

${ }^{3}$ O Comitê de Normas de Auditoria do AICPA aprovou a nova Declaração de Normas de Auditoria No 99 (SAS 99) que contém considerações sobre fraude em auditoria financeira que antes estava regida pelo SAS 82. A nova norma começa a vigorar a partir das auditorias iniciadas a em 15/12/02. 
como: "Em nossa opinião...”; “...nossos exames foram conduzidos de acordo"; "...considerando a relevância dos saldos...".

Tanto para os usuários conhecedores dos aspectos técnicos como para os menos advertidos, o trabalho do auditor representa uma garantia adicional relativa e independente que Ihes permite tomar decisões com maior confiança do que teriam sobre as demonstrações contábeis não auditadas. Talvez isso seja conseqüência do significado, tanto técnico como semântico, de uma frase incluída no parecer do auditor, mais especificamente quando se afirma que "as demonstrações financeiras apresentam adequadamente, em todos aspectos relevantes, a posição patrimonial e financeira ..." oferecendo uma idéia de que tudo está certo nas contas da entidade.

Diante dessa afirmação do auditor, os usuários passam a ter a sensação de segurança de que as demonstrações contábeis não contém manipulações e isso pode lhes assegurar a confiança necessária para tomada de decisões. Para enfatizar a idéia, o auditor conclui o parágrafo citado de seu parecer dizendo que as demonstrações contábeis estão "de acordo com os princípios fundamentais de contabilidade" ou "de acordo com as práticas emanadas da legislação societária", "aplicados de forma consistente ou uniforme com os aplicados no exercício anterior", o que permite a seus usuários realizar qualquer análise comparativa, tanto em termos relativos como absolutos, com garantia de que haverá continuidade.

É nosso entendimento que o referido parecer apresenta indicações de obsoletismo diante do fenômeno da contabilidade criativa. Esse entendimento se sustenta na constatação do significado da contabilidade criativa e de seus efeitos no poder informativo dos relatórios contábeis e financeiros das entidades, onde observamos perplexos a falta de qualquer referência a esse tipo de prática. Nossa afirmação anterior consegue sustentação nas idéias de autores anteriormente citados, mais especificamente Monterrey, quando afirma que a prática da contabilidade criativa exige o descumprimento dos princípios e normas contábeis ou abandono da aplicação uniforme dos mesmos. Esta situação exigiria parágrafos de ênfase ou ressalvas na opinião do auditor, claro que no caso de alterações que pudessem ser consideradas relevantes.

Diante da generalização de práticas criativas, entendemos que os auditores deveriam refletir sobre a possibilidade de considerar em seus pareceres a indicação específica da inexistência de contabilidade criativa, mesmo entendendo que a opinião do auditor se baseia no relatório por exceção; isso significa dizer que só se inclui no relatório aquilo que não é adequado aos princípios e normas contábeis. Entendemos que a necessidade de se incluir informação referente à existência ou não de práticas criativas levará o auditor a ajustar seus planos de auditoria, obrigando-os a buscar provas específicas para detectar tais práticas. Isso poderá ajudar a diminuir a imagem de "posição cômoda", "complacente" ou até de "cumplicidade", entendida por muitos cidadãos diante desse fenômeno, agravada ainda mais pelos últimos escândalos.

As empresas de auditoria, e os auditores em geral, têm sido alvo de fortes críticas da opinião pública especializada pela posição tomada diante da problemática da contabilidade criativa. Alguns justificam suas críticas a esses profissionais pela atitude complacente, para outros até pouco profissional, frente à existência de práticas criativas por parte dos administradores das empresas. Há casos em que os auditores chegaram a ser acusados de cúmplices dos administradores. A essa discussão pode-se adicionar que é bastante comum empresas entrarem em processo concordatário ou falimentar depois de apresentarem pareceres de auditoria totalmente limpos e sem ressalvas.

A imensa gama de incentivos existentes ou a falta de sanções específicas para quem manipula informações contábeis, seja qual for o motivo, nos permitem inferir que o fenômeno da contabilidade criativa é de difícil erradicação. $A$ isso deve ser acrescido que no futuro tais práticas deverão ser cada vez mais sofisticadas, o que nos faz prever que serão mais difíceis de identificar ou descobrir. Se isso é verdade para os profissionais da auditoria, o que então pensar das dificuldades que representarão para os usuários não afeitos às práticas contábeis tradicionais? Dentre as normas internacionais de auditoria promulgadas pelo IFAC, existe uma denominada "Fraude e erro", que têm como objetivo o estabelecimento de 
normas e a proposição de orientação sobre a responsabilidade do auditor ao contemplar fraude e erro em uma auditoria de demonstrações contábeis. A norma de auditoria americana "Statement on Auditing Standard” (SAS n. 82/1996), publicada pelo Instituto Americano de Contadores Públicos Certificados (AICPA), estabelece uma clara diferença entre erro e fraude. A diferença fundamental está na intenção da prática da irregularidade, tornando-a sinônimo de fraude. Deve-se lembrar que esse componente "intenção" é considerado por Laínez - citado anteriormente - como um dos requerimentos básicos que servem para qualificar uma prática contábil como contabilidade criativa. Por outro lado, o erro deve ser entendido como simples omissões involuntárias, com efeitos que raramente são relevantes nas demonstrações contábeis.

A norma internacional de auditoria do IFAC, anteriormente citada, define o termo fraude como "Um ato intencional ...". A norma ainda adiciona que "A fraude pode envolver manipulação, falsificação ou alteração de registros e documentos; apropriação indébita de ativos; supressão ou omissão de efeitos de transações nos registros e documentos; registro de transações sem comprovação e aplicação indevida de políticas contábeis."

Diante dessa situação, o auditor deve incluir em seu plano de trabalho procedimentos específicos que visem a identificar, ao menos, a existência das práticas de contabilidade criativa mais comuns, adaptando tais provas aos riscos inerentes de cada setor, empresa ou negócio. Na pressuposição de que o auditor agregue em seus planos de auditoria procedimentos que permitam identificar práticas criativas, e que a administração se negue a corrigi-las, o auditor deverá incluir em seu parecer a respectiva ressalva ou parágrafos de ênfase que julgar necessários. Dependendo dos valores envolvidos poder-se-á chegar até a negativa da opinião. Tal posição do auditor exporá a empresa e poderá fazer com que ela reveja sua posição em relação às práticas de manipulação da informação contábil.

Algumas medidas de controle também têm sido sugeridas para minimizar as possibilidades de práticas de contabilidade criativa. A década de 90 foi profícua na publicação de documentos relacionados com as novas filosofias de controle interno nas organizações. Uma das sugestões que encontramos é a descrição de Comitês de Auditoria com funções estritamente de controle. Isso poderia minimizar a falta de confiança que os usuários têm nas demonstrações contábeis preparadas pela administração e a pouca garantia que os auditores oferecem através de seus relatórios. Outra ação de controle que tem sido identificada e utilizada nesse sentido é a de incorporação de pessoas independentes nos Conselhos de Administração e Fiscal, também denominada de governança corporativa. Entendemos que a posição do auditor independente frente à existência da contabilidade criativa nas empresas que audita não é nada fácil.

Nos casos em que a prática da contabilidade criativa está dentro da margem de legalidade, devido à diversidade de alternativas e opções oferecidas pela contabilidade, o auditor estará tecnicamente impossibilitado de considerá-la em seu parecer. Na verdade, nesse caso, ao auditor só restaria utilizar seu relatório como uma forma de pressionar os administradores, pois, por razões óbvias, tais administradores não estarão dispostos a ver seus relatórios com ressalvas ou parágrafos que possam colocar sua contabilidade sob suspeição.

Deve-se lembrar que, mesmo para o auditor, cujo acesso é irrestrito à informação que considere necessária para suportar sua opinião - caso contrário, produzir-se-á uma limitação ao trabalho e, por conseguinte, uma ressalva - é bastante difícil identificar as práticas de engenharia contábil. Um dos aspectos que sustentam esta afirmação é a dificuldade de se identificar a verdadeira intenção que tem o administrador em optar por um ou por outro princípio ou norma contábil.

Uma das sugestões feitas por diferentes comissões de auditoria, no âmbito internacional, é a implementação de Comitês de Auditoria e a participação de auditores, como conselheiros independentes, nos Conselhos de Administração, além de elaborar sofisticados códigos de comportamento ético e promover sua efetiva aplicação. Desta maneira se evidencia, uma vez mais, que o problema se encontra principalmente no desvirtuamento dos valores éticos e morais dos profissionais e também da sociedade na qual se desenvolvem. Em outras palavras, quer nos parecer que o problema a ser considerado é muito mais de caráter ético do que técnico. 


\section{CONCLUSÕES}

Pode-se concluir que o papel do auditor independente, frente ao fenômeno das práticas de contabilidade criativa nas demonstrações contábeis de seus clientes, não é nada fácil de definir. De qualquer forma, esse é um tema que os auditores deverão enfrentar com muita coragem e determinação, sob pena de aumentar a perda de confiança e o abismo entre o trabalho por eles produzido e as expectativas dos usuários.

O problema da contabilidade criativa parece ter sua origem na crise de valores éticos e morais da sociedade contemporânea, mais do que na indefinição técnica e normativa. Ainda assim, queremos declarar nossas esperanças no comportamento ético do profissional que elabora as demonstrações contábeis, ainda que pareçam pouco otimistas. É possível inferir que as práticas de contabilidade criativa não são casuais e são realizadas, na maioria dos casos, para distorcer e modificar a "imagem fidedigna" de uma entidade, podendo até fazer parte de políticas e estratégias empresariais no sentido de modificar ou interferir na visão ou percepção que terão os usuários a partir da informação contábil.

Estamos convencidos de que a normatização e a harmonização contábil poderão contribuir de forma muito positiva. A redução de alternativas de escolha entre princípios e práticas contábeis, entre as regras específicas de valoração de ativos e passivos, entre os critérios de amortização etc. deverão influir de forma determinante, principalmente porque a prática da contabilidade criativa encontra campo fértil na ambigüidade ou inexistência de normas. Esta cada vez maior limitação à contabilidade criativa deverá trazer maior qualidade às informações analíticas disponibilizadas aos usuários, já que limitará, cada vez mais, o conceito abstrato e subliminar da "imagem fidedigna" do patrimônio.

A crescente perda de credibilidade e confiança por parte dos clientes e usuários no trabalho do auditor, muitas vezes motivada pela falta de qualidade dos trabalhos ou relatórios, tem aumentado as expectativas e influenciado de forma importante um número cada vez maior de processos judiciais contra auditores e empresas de auditoria.
O parecer de auditoria é a principal ferramenta do auditor para cumprir a norma e relatar o produto de seu trabalho. Atualmente, o parecer de auditoria não contempla qualquer informação relacionada à Contabilidade criativa e essa é a principal razão para nosso entendimento de que há certo grau de obsoletismo em sua forma e conteúdo. Felizmente, nos dias atuais estão sendo desenvolvidos estudos no sentido de se modificar o modelo-padrão de parecer que vem sendo utilizado há anos. A inclusão de frases que indiquem que o trabalho realizado pelo auditor pode ou não estar considerando práticas de contabilidade criativa deveria constar das próximas modificações.

Finalmente, queremos destacar que, pela contribuição que representou, representa e continuará representando o trabalho dos auditores para a sociedade, os profissionais dessa área não poderão se furtar a reconhecer que é chegada a hora de fazer as mudanças que estão sendo requeridas. Capacitação técnica temos certeza que existe, e de sobra; o momento é de uma decisão que possa acompanhar a evolução dos negócios e o ritmo da globalização, sem o ranço de um conservadorismo que está na hora de ser enfrentado. 


\section{REFERÊNCIAS BIBLIOGRÁFICAS}

AMAT, O; BLAKE, J. Contabilidad Creativa. 3. ed. Barcelona: Gestión 2000, 1999.

AMAT, O; BLAKE, J.; DOWDS, J. The ethics of creative accounting. Ethical Issues in Accounting, Barcelona, p.24-40, 1999.

AMAT, O.; BLAKE, J.; MOYA, S. La Contabilidad Creativa en España y en el Reino Unido. Un estudio empírico. Barcelona Management Review, Barcelona, n.3, p.68-75, 1996.

AMAT, O.; BLAKE, J.; OLIVERAS, E. Reflexiones en torno al contenido de la imagen fiel. Técnica Contable, v. 49, n. 578, p. 81-90, febrero 1997.

AMAT, O.; MOYA, S; BLAKE, J. La Contabilidad Creativa. Partida Doble, n.79, p.24-32, junio 1997.

A.I.C.P.A. Declaraciones sobre normas de Auditoria: Statement on Auditing Standard № 82, 1977. In: La responsabilidad del auditor ante los fraudes y las irregularidades, IMCP.

BASTANTE, V. La Responsabilidad del Auditor ante los Fraudes y Errores al efectuar la Auditoria de los Estados Financieros, Norma Internacional de Auditoria No 240 de Marzo de 2001, emitida por el IFAC.

BUENO, E. De la contabilidad creativa al delito contable. Partida Doble. 1998.

CANO, Manuel Análisis de la fiabilidad de la información contable: La contabilidad creativa. Madrid: Prentice, 2002.

CARMICHAEL, D. R.; WILLINGHAM J.; SCHALLER C. Auditing: Concepts and methods. New York:: McGraw-Hill, 1996.

DAVILA G., M. La auditoria comprehensiva: un moderno concepto en la auditoria gubernamental. México: IMCP, 1991.
DEL CID GOMEZ, Juan M. Extensión de la responsabilidad del auditor: implicaciones y estrategias defensivas. Técnica Contable, Vol. 46, № 4, 1994.

FERREIRA, Aurélio B. H. Novo Dicionário da Língua Portuguesa. Editora Nova Fronteira.

GRIFFITHS I. New creative accounting. How to make your profits what you want them to be. London: McMillan Press Ltd., 1995.

Contabilidad Creativa: cómo hacer que los beneficios aparezcan del modo más favorable. Bilbao: Ediciones Deusto, 1998.

GUEVARA, I. R. Responsabilidad de la auditoria y del auditor. Universidad Centroccidental "Lisandro Alvarado", Venezuela, 1996.

Auditoria de Gestão: utilizando de indicadores de Gestão no setor público. Caderno de Estudos da FIPECAFI, Universidade de São Paulo, v.11, no 21, p 24-41, maio-agosto, 1999.

IBRACON - Instituto Brasileiro de Contadores. Princípios Contábeis e Normas e Procedimentos de Auditoria. São Paulo: Atlas, 1988.

IFAC. Normas Internacionales de Auditoria: Emitidas por el comité internacional de prácticas de auditoria, IMCP, 3ae ed., 1997.

JAMESON, M. A practical guide to creative accounting. London: Kogan Page, 1988.

KNECHEL, W. R. Auditing Text and Cases. SouthWestern College Publishing. International Thomson Publishing Company, Cincinatti, Ohio, 1997.

LAINEZ, J. A.; CALLAO, Susana. Contabilidad Creativa, Cívitas Ediciones, Madrid, España, 1999. 
MONTERREY MAYORAL, J. Entre la Contabilidad Creativa y el delito contable: la visión de la Contabilidad privada. Trabajo presentado en el V Seminario Carlos Cubillo, Universidad Autónoma de Madrid, 1997.

NASER, K. Creative Financial Accounting: its nature and use. London: Prentice-Hall, 1993.

SHAFER, W.; MORRIS R.; KETCHAND A. Effects of personal values on auditors' ethical decisions. In: Accounting, Auditing \& Accountability Journal, Vol. 14, № 3, 2001.
SIERRA, G.; PEREZ M. y ORTA M. El dilema ético: Factores determinantes del comportamiento del auditor. In Actualidad financiera, Vol. 6, № 7, Julio 2001.

SMITH, T. Accounting for growth. London: Century Business, 1992.

STATEMENT ON AUDITING STANDARD № 99 "Las Normas de Auditoria", <http://www.redcontable.com/ red/article.php?sid=104>.

TÚA PEREDA, J. Algunas precisiones adicionales en torno al principio de imagen fiel. Técnica Contable, $\mathrm{p}$. 441-484, diciembre 1985. 